\title{
PROMISING ADVANCES OF AMAZONIAN MONITORING SYSTEMS THROUGHOUT VANGUARD TECHNOLOGY AND SCIENTIFIC KNOWLEDGE
}

\author{
L. S. Soler, D. E Silva, C. Messias, T. C. Lima, B.M.P. Bento, J.J. de Souza, J. Doblas, D. Moraes, C. Almeida ${ }^{1}$ \\ INPE, National Institute for Space Research, Av. dos Astronautas 1754, São José dos Campos, 12227-010 Brazil \\ lusoler@gmail.com,daniel.silva@inpe.br, cassiano.messias@inpe.br, carvalholimatcl@gmail.com, brunapechini@gmail.com, \\ jeff_0110@hotmail.com, juandb@gmail.com, moraesdrv@gmail.com, claudio.almeida@inpe.br
}

KEY WORDS: Deforestation, Monitoring, PRODES, DETER, Visual Interpretation, Amazon, Machine Learning

\begin{abstract}
:
PRODES and DETER project together turned 33 years-old with an undeniably contribution to the state-of-art in mapping and monitoring tropical deforestation in Brazil. Monitoring systems all over the world have taken advantage of big data repositories of remote sensing data as they are becoming freely available together with artificial intelligence. Thus, considering the advent of new generation remote sensing data hubs, online platforms of big data that can fill in spatial and temporal resolutions gaps in current deforestation mapping, this work aims to present recent innovations at INPE's deforestation monitoring systems in Brazil and how they are gauging new realms of technological levels. Recent innovations at INPE's monitoring systems are: 1) the development of TerraBrasilis platform of data access and analysis; 2) the adoption of new sensors and cloud detection strategies; 3) the complementary use of multi-sensor images; 4) the complementary adoption of SAR C-band images using cloud data to sample and process Sentinel-1. Future innovations are: 1) development of a Brazilian data cube to be used in deep learning techniques of image classification; 2) Routine uncertainty analysis of PRODES data. Automatization might fasten mapping process, but the real challenge is to succeed in automatization maintaining data quality and historical series. The hyper-availability of remote sensing data, the initiative of a Brazilian Data Cube and promising machine learning techniques applied to land cover change detection, allowed INPE to reinforce its central role in tropical forest monitoring.
\end{abstract}

\section{INTRODUCTION}

In 2021, PRODES project, in portuguese Projeto de Monitoramento do Desmatamento na Amazônia por Satélites (Almeida et al., 2021), the most famous Brazilian deforestation project undertaken by INPE, turned 33 years-old, with an undeniably contribution to the state-of-art in mapping and monitoring tropical deforestation in Brazil using Landsat images with a minimum area detected of 6,25 ha (Kintisch, 2007, Ometto et al. 2011,). As a political response to socioenvironmental and international pressures, the Brazilian government operationalized in 2004 DETER (Sistema de Detecção do Desmatamento em Tempo Real na Amazônia). DETER is a complementary system to PRODES that operated in the first years with a minimum deforested area detected of 25 ha in a daily basis using MODIS images, enabling quick deforestation alerts. After 2015, the minimum area detected enhanced to 3 ha using WFI sensor on-board of ChineseBrazilian satellite CBERS-4, as well as, AWiFS sensor onboard to Indian Remote Sensing Satellite (IRS) (Diniz et al., 2015, Valerino et al., 2016).

INPE's transparency regime enabled technology transfer and supported environmental governance in Brazil and elsewhere (Rajão and Gerogiadou, 2014). Training courses have been provided to countries like Guiana, Suriname and Peru in South America, Congo in Africa and even in Italy, Europe. INPE also takes part of discussions about monitoring programs implementation in some countries with tropical forests.

Nowadays, a number of land cover change monitoring systems supported by research organizations have been implemented to map deforestation, not only in Brazil, but also in and other countries in the Americas, Africa and Asia (Hansen et al., 2013). In such systems it has been mandatory the use of big data repositories of freely available remote sensing data together with artificial intelligence (Portillo-Quintero et al. 2021).

Thus, considering the advent of new generation remote sensing data hubs, as well as the fast development of online platforms to deal with big data and gaps in spatial and temporal resolutions suitable for mapping deforestation, INPE's monitoring team have developed a number of studies aiming to explore the vanguard in science and technology, which are briefly discussed in this paper.

In this context, this work aims to present recent innovations at INPE's deforestation monitoring systems in Brazil and how they are gauging new realms of technological levels in terms of data and methods. Published and on-going advances are listed, with their gains and set-backs presented and briefly discussed.

\subsection{Deforestation, governance and capacity building}

The successful long-term environmental surveillance in the Brazilian Amazon forests has guaranteed international funds to promote socioecological development and decrease the depletion of natural resources. The continuity of PRODES and DETER during three decades could only be possible due to human capacity building and vanguard in science \& technology (Almeida et. 2020). Since 2004, PPCDAM governmental program has implemented land planning activities together with deforestation monitoring and control actions. Nowadays, it has been recognized as contributing to decrease deforestation in the region by $80 \%$ between 2004 and 2012 (Messias et al., 2021a; West and Fearnside, 2021).

Messias et al. (2021b) evaluated the spatial distribution of deforestation in the BLA until the last century and over the last two decades, through identification of areas where increments 
of original forest suppression are concentrated. Results demonstrated that the most impacted forests until 2001 were mainly in the South and East of BLA, in the largest expansion frontier called 'arc of deforestation'. For the last two decades the arc has moved toward the center of Pará, the South of Amazonas and the North of Rondônia, indicating new fronts in forests deep inside the BLA. Another study that indicates new fronts of deforestation spatial location was performed by Messias et al. (2020).

Messias et al. (2021b), analysed deforestation rates in the Brazilian Legal Amazon (BLA) since 1988 using PRODES historical series. Results showed that in the first twenty years the deforestation rates were higher than ten thousand $\mathrm{km}^{2}$ per year, but decrease significantly from 2005 to 2012 due to the commodities' crisis and law enforcement policies with on-field control. The rise of deforestation rates after 2013 are linked to the world economic, land speculation, rising demand of agricultural commodities and loosening of environmental legislation. Authors indicated that $20,62 \%$ of the original forests located in BLA had been suppressed by 2020, where Pará, Mato Grosso, Maranhão and Rondônia states witnessed the highest forest coverage losses.

Up until 2013, during the golden years of PPCDAM, governmental actions expanded PRODES project allowing INPE to establish a complementary near-real time alert system DETER, and also to begin deforestation monitoring in Cerrado (INPE, 2021a). In the last couple of years the decreased investments in PPCDAM make it hard, but did not prevent INPE and partners to expand the systematic vegetation monitoring to the other Brazilian biomes, using PRODES methodology (FUNCATE, INPE, 2021) and supported by Amazon Fund. After 2010, PPCDAM have been largely complemented by the Amazon Fund and more recently by capacity building and research resources from the National Council of Technological and Scientific Development - CNPq.

Since 2019, PPCDAM and INPE's budget together with overall governmental funds for research have decreased significantly, which rise a number of speculations about the continuity of forest surveillance in Brazil. The continuation of PRODES with financial resources still depends upon PPCDAM, and is necessary to maintain the modern team of remote sensing and vegetation experts that has engaged in bringing advances to PRODES/DETER monitoring systems.

\subsection{A brief history of deforestation monitoring in Brazil}

In the late 70s, Tardin et al. (1979) published a method to monitor tropical deforestation in Brazil, revealing the feasibility of Landsat-3 satellite to map deforestation in the Brazilian Amazon. Between 1988 and 2000, PRODES project was established to map clear cut annual deforestation adopting visual interpretation, resulting in annual output maps at the spatial scale 1:250.000 using Landsat satellite images provided by NASA (https://earthexplorer.usgs.gov/) or INPE's repositories (http://www.dgi.inpe.br/CDSR/). After 2002 all produced data and methodology became freely available online, establishing a national landmark of INPE's transparency in data generation and distribution (Maurano et al., 2019). Today, an interdisciplinary team of experts compose a miscellaneous package of knowledge in remote sensing, geomatics, ecology, geography, phytophysiognomy, computing science, machine learning and else, all dedicated to improve annual mapping of deforestation as well as near real-time detection in the Brazilian Amazon and other biomes in the country (Almeida et al., 2020).

Just like in its very beginning, current PRODES project methodology is yet based on visual interpretation, which is sometimes mistaken as a burden that prevents complete automatization. Visual image interpretation techniques adopt inherent knowledge of more than three decades, which are based in interpretation keys focused on colour, texture, shape and context that all together characterize and allow the detection of deforestation features. Data mining and pattern recognition algorithms have been tested aiming to take advantage of such accumulated knowledge over time, however visual interpretation in Brazilian forest monitoring systems still plays an important role that guarantee confidence level and allow validation and uncertainty analysis to the process (Maurano et al, 2019, 2020).

The interpreters and auditors run the mapping process in a distributed and multi-user environment named TerraAmazon (http://www.terraamazon.dpi.inpe.br/) developed in TerraLib that is an Open Source Library developed by INPE (http://www.terralib.org) and distributed under GNU LGPL license (Camara et al., 2008, Freitas et al. 2007). TerraAmazon runs online and offline (an adaptation required due to COVID19 pandemic period) and manages the complete flux of data, processes, and users required to produce land cover mapping projects. The software allows an interactive data work flow and a customized vector edition, which speeds interpretation and increases efficiency and data quality.

Despite critics to visual interpretation methods, past experiments in PRODES project adopting semi-automatic image classification frequently resulted in a big number of omission and/or commission errors. These misclassification errors due to the lack of contextual information were then fixed by visual interpretation, which resulted in a substantial time consuming with no significant gain, and plus at the risk to produce systematic errors of false positive areas of deforestation. Thus, the need to keep consistency in historical PRODES data series of deforestation in Brazil that support governance UNFCC negotiations, allowed the deserved credit to the multi-decadal expertise built over these years in image interpretation. Such valuable knowledge has been assimilated to map all other Brazilian biomes adopting rather semiautomatized methods (Almeida et al. 2020).

Therefore, visual image interpretation is a big foundation of confidence level of Brazilian monitoring systems, as the main objective is to avoid at maximum false positives deforested patches, and at the same time prevent omissions or true negatives. Complemented methods of cloud detection, image classification mostly to deal with cloud coverage are discussed next.

\section{INNOVATION AND ADVANCES IN BRAZILIAN MONITORING SYSTEMS}

Among recent innovations at INPE's monitoring systems one can mention: 1) the development of TerraBrasilis, an online platform of data access and analysis (Assis et al., 2019); 2) adoption of new sensors and cloud detection strategies; 3 ) the complementary use of multi-sensor images in DETER system to provide faster, more and more precise deforestation alerts in hotspot regions; 4) the complementary adoption of SAR C-band 
images within DETER project cloud data to sample and process Sentinel SAR images.

\subsection{TerraBrasilis online platform}

In 2005, INPE's team develop the first version of the opensource multi-user environment TerraAmazon platform, which became an essential tool to allow a number of interpreters to work together in the same spatial database, at the same time. However, after twenty years of spatial data generation in PRODES and DETER projects, there was an urgent need to organize, analyse and publish these data in a clever and userfriendly way. Thus, in 2019 INPE released TerraBrasilis, an online spatial data infrastructure that provides PRODES and DETER data access and interfaces to geographic systems and data analytics landed on complex algorithms (Assis et al., 2019; INPE, 2021b).

Data dissemination is an essential condition for quality insurance of PRODES/DETER products, together with mapping process requirements and external validation. The TerraBrasilis platform allows anybody to access, use, analyse and check the data, therefore reassuring transparency to INPE's deforestation monitoring systems. Figures 1 and 2 show examples of graphical outputs of spatial and temporal statistics of deforestation that can be retrieved within different spatial partitions. TerraBrasilis can be accessed at http://terrabrasilis.dpi.inpe.br.

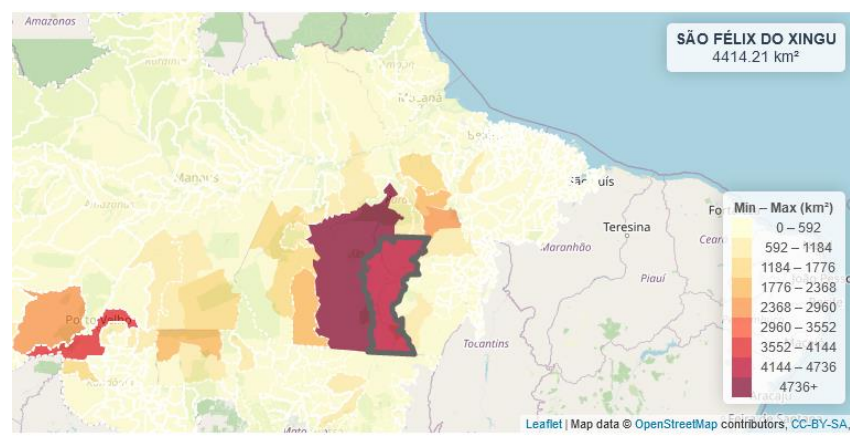

Figure 1 - Output map derived from TerraBrasilis platform showing the top ten municipalities in the BLA with the highest rates of deforestation according to PRODES 2019-2020 data. The interactive map shows figures for each municipality separately, in this case São Félix do Xingu was selected.

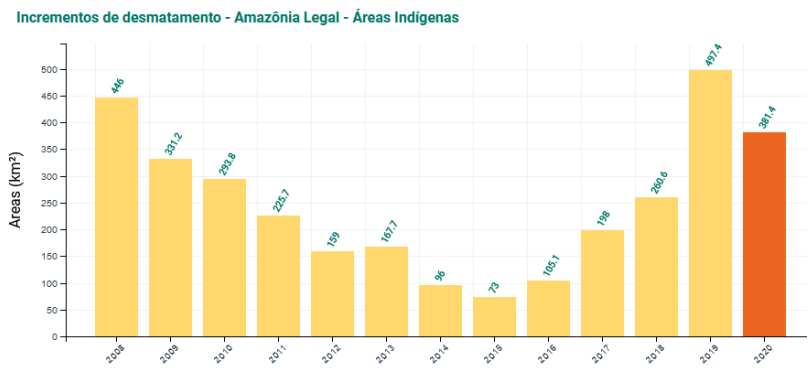

Figure 2 - Output map derived from TerraBrasilis platform showing PRODES deforestation increments in indigenous lands in the BLA between 2008-2020.

\subsection{Adoption of new sensors and cloud detection strategies}

Until 2017, PRODES only used Landsat satellite images, with an average number of 220 images per year, considering it is selected a single scene per Landsat tile per year. Indeed every year around $5 \%$ of area in PRODES annual maps has been affected by cloud coverage, and even though these areas are usually far from deforestation hotspots, the PRODES methodology takes into account the non-observed area to calculate the annual rate of deforestation (Almeida et al., 2021). Annual cloud cover variation is usually associated to effects of large scale oceanic-atmospheric phenomena El Niño and/or La Niña, however, the northern portions of the Amazon show recurrent cloud coverage during subsequent years. As the arc of deforestation expands towards this region among others, there was an increasing interest in reducing the non-observed area in the monitoring program.

In the PRODES project, a strategy was adopted to deal with unobserved areas due to cloud cover. Images that contain a significant amount of cloud cover have gained complementary images to allow observing the areas under the clouds and its shadows. This is possible because the complementary image might be free of clouds in areas previously covered by clouds. Any complementary image must have a date close to main image acquisition date.

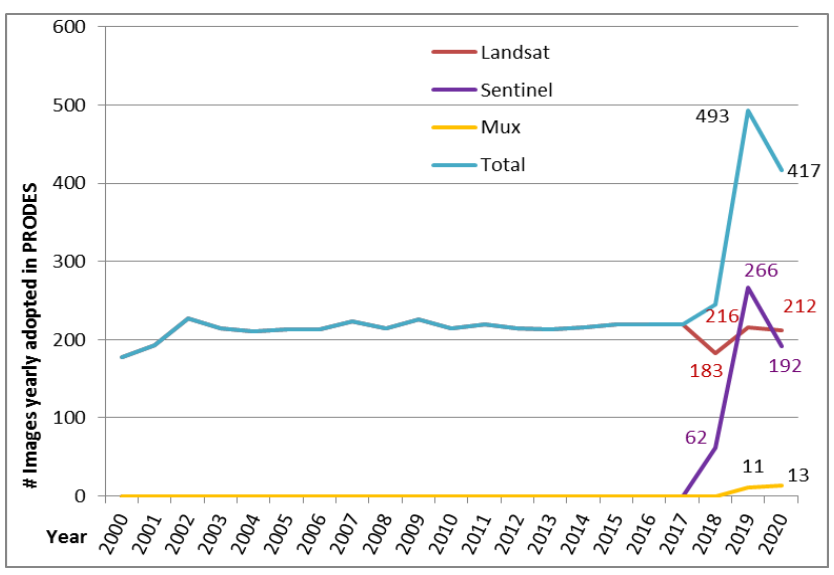

Figure 3. Number of adopted images in PRODES project since 2000 according to sensor and year.

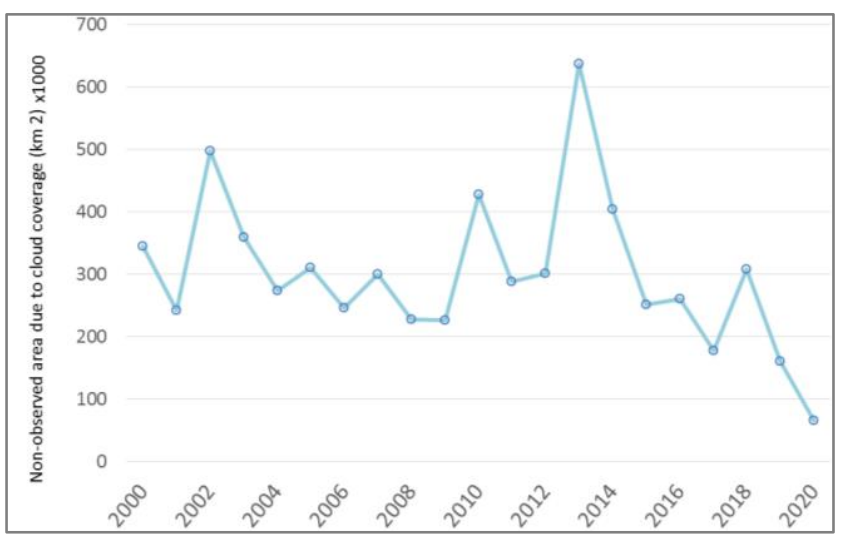

Figure 4. Non-observed areas in $\mathrm{km}^{2}$ (or areas under cloud cover) between 2000 and 2020* in PRODES annual maps. * estimated value as final maps for 2020 are yet unpublished.

With the advent of new satellite images with a Landsat class spatial resolution (20 to $30 \mathrm{~m})$ and similar spectral band characteristics, and the facility to use more than one image in a given spatial unit by the TerraAmazon platform, PRODES started to significantly increase the number of images since 2018 (Figure 3) to reduce the gaps of non-observed areas in the 
Amazon. The Sentinel-2B/2A MSI from European Space Agency and CBERS-4/4A MUX from INPE, are now used as complements of Landsat-8 OLI images, as part of a new methodological step in PRODES. As a result, the non-observed area (cloud and shadow) in the PRODES annual maps fell to $50 \%$ in relation to the $2000-2018$ average (Figure 4). The expected value for PRODES 2020 is a further reduced value, lower than $25 \%$ compared to the average of the last two decades.

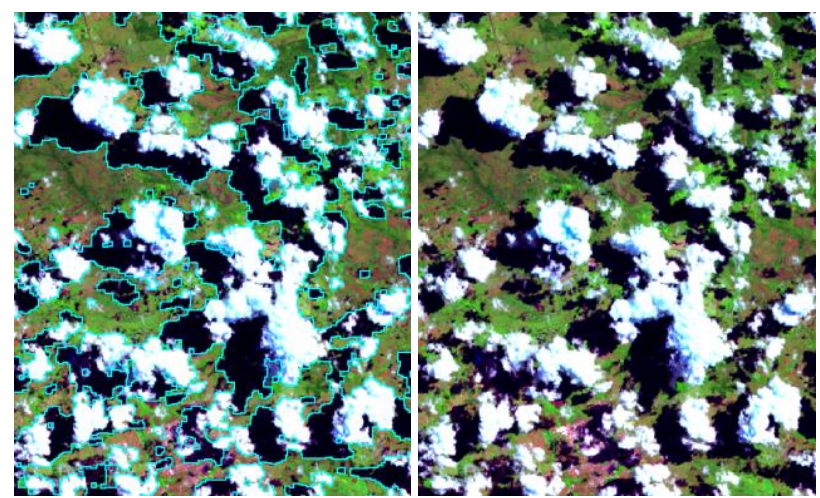

Figure 5 - Output cloud and shadow classification derived from Cloud Detection Tool (left) and Landsat-8 image (right) adopted showing high density of cloud coverage.

In order to assist the new demands, especially the mapping of the cloud and shadow classes of a greater number of images, an algorithm, named Cloud Detection Tool (Abreu et al., 2013), was developed by INPE and FUNCATE (Foundation for Science, Technology and Space Applications). The Cloud Detection Tool, implemented in the TerraAmazon software, is of great value regarding the reduction of the time spent in mapping and the maps quality, making the cost/benefit relationship of the new methodological step profitable. Figure 5 shows a classified Landsat image using cloud detection algorithm that is used as a mask to map deforestation in the surrounding areas. After visual interpretation a complementary image is selected in a way that contains the least percentage of clouds possible underneath the interpretation mask initially adopted, based on cloud detection mask derived from the first image.

\subsection{DETER system innovations with optical images}

Changes in spatio-temporal dynamics (Dias et al., 2016; Godar et al., 2014) and patterns (Rosa et al., 2012; Kalamandeen et al., 2018) of deforestation, the recent increase in deforestation annual rate in the BLA (INPE, 2021b) and the scarcity of financial resources for deforestation combat-and-control actions emphasized the need to provide to the environmental agencies adapted solutions in vegetation change monitoring. In this context, DETER was designed as an early warning system to support surveillance and control of deforestation, mapping the occurrence of clear-cutting and forest degradation, and guiding law enforcement efforts on the ground (Diniz et al., 2015).

From 2004 to 2017 DETER operated based on MODIS sensors on-board of Terra/Acqua satélites, under $250 \mathrm{~m}$ of resolution. Despite rough spatial resolution, during this period DETER generated more than 70000 alerts accounting for $88000 \mathrm{~km}^{2}$. In 2015, DETER started using imagens from WFI sensor on-board of CBERS-4/4A, under $64 \mathrm{~m}$ of spatial resolution. It allowed the distinction between deforestation and forest degradation and a minimum area mapped of 3 hectares. In 2021, Amazonia-1 satellite shall provide $60 \mathrm{~m}$ resolution images, better revisiting period and likely less cloud cover limitation, which will decrease the delay between deforestation occurrence and detection. Nevertheless, it can be said that DETER system is already capable of detect, map and alert forest disturbance up to 3 hectares, in a near-real time platform.

In addition, INPE is developing a new near early warning monitoring system to detect deforestation and degradation in the Amazon forest, named DETER intenso, based on DETER methodology and using multi-satellite data (INPE, 2021b). Using Landsat-8 OLI, Sentinel-2A/2B MSI, CBERS-4/4A MUX and WFI image data, the system is able to focus on and adapt to priority areas for combat and control field actions, and provide faster, more and more precise alerts to the environmental agencies. This operational monitoring system improved significantly the governmental response INPE is able to provide to society throughout its monitoring program, which resulted from INPE's multidisciplinary competencies and innovations.

DETER intenso is based on a WebGIS platform named Forest Monitor that allows the access, visualization and vector mapping on multi-satellite images, available in cloudcomputing environment provided by Amazon Web Services (AWS). In this system, the cloud cover impact on visual interpretation process was minimized, the revisit period decreased to 1 or 2 days and the interval between the dates of deforestation occurrence, detection and alerts supply was reduced.

\subsection{Near-real time detection - DETER program using SAR}

As part of DETER system, DETER-R is a recent pilot project that uses open-accessed SAR images of Sentinel satellites and applies RS techniques for automatic near-real time detection of deforestation (Doblas et al. 2020). The objective is to provide data to monitor deforestation and forest degradation during cloudy season, when optical sensors detection is limited. In this project, the key processes for warning mapping, from the image data access to the polygon supply to the environmental agencies is automatic. The developed algorithm uses cloud computing. This methodological improvement of the DETER system allowed to provide more warnings with higher precision during the rainy season, important to support field actions of environmental agencies.

\section{FORTHCOMING INNOVATION AND CHALLENGES}

Regarding the on-going advances under development by INPE's team are relevant to list: 1) development of a Brazilian data cube to be used in deep learning techniques of image classification; 2) routine uncertainty analysis of PRODES data.

\subsection{Development of a Brazilian data cube}

INPE's skills and experiences in Earth Observation (EO), Remote Sensing (RS), vegetation sciences and Data Base Management System (DBMS) development, have given a central role to the Institution in tropical forest monitoring. INPE's researchers provided solutions to process high volume and diversity RS data available for EO (Câmara et al., 2008; Vinhas et al., 2017), which exponentially increased during the 
last two decades (Claverie et al., 2018; Defries and Townshend, 1999; Hansen and Loveland, 2012). The benefit of this data hyper-availability for land cover monitoring developed at INPE was combined with the recent innovations in DBMS for Big Data and cloud computing for EO (Ferreira et al., 2020a), as the Brazilian Data Cube project (BDC) that provides RS Analysis Ready Data (ARD) (Ferreira et al., 2020b).

Land cover change monitoring can be significantly improved with the emergence of efficient approaches applied to ARD, and the automatization of image access and processing (Picolli et al., 2020; Sanchez et al., 2019).

Several studies showed the potential of satellite images temporal series in land use and land cover mapping. Recently, Machine Learning techniques have been trivialized. Support Vector Machine (Mountrakis et al. 2011), random forest (Belgiu and Drăguţ 2016) and deep learning (Adarme et al. 2020, Sanchez et al. 2019, Goodfellow et al. 2016) correspond to the most interesting techniques in such monitoring approach. The SITS package (Satellite Image Time Series), that operates in $\mathrm{R}$ software, offers tools for analysis, visualization and classification of satellite image time series organized in data cube (Câmara et al., 2018).

In this way, the Brazilian Monitoring Program seeks to integrate $\mathrm{BDC}$ services and data in the processes flow for deforestation mapping.

\subsection{Uncertainty analysis of PRODES data}

The evaluation of mapping accuracy and a consequent uncertainty analysis contribute to data quality improvement. PRODES project has been evaluated by adopting a stratified sampling and visual validation (Maurano et al., 2019). However, it is understood that accuracy and uncertainty analyses should be undertaken at a regular pace in order to assure the final user data quality and robustness. Besides, such analyses shall be extended to DETER systems.

\section{CHALLENGES}

Hereby we list some challenges that must be tackled by INPE's team aiming to implement even faster and more confident deforestation monitoring systems in Brazil.

Technical and scientific knowledge accumulated over time through visual interpretation are feasible to be incorporated in semi-automatized systems throughout objected-oriented image classifiers (Maurano et al, 2020), what will require a dedicated team and time to build up data cubes feature libraries. This could diminish uncertainties and time consuming in generating annual increments of deforestation.

Indeed, the operational cost of PRODES and DETER for the Amazon is lower than 0.04 USD per monitored $\mathrm{km}^{2}$ (Almeida et al., 2019), many aspects justify to fully or partially automate these monitoring projects. It can lower the risk of human failure in the sequence of processes prior to the deforestation detection, by systematizing these processes and by running efficient routines that check data consistency. PRODES production agenda forecasts to publish the map and rate for the whole Amazon of a given year in the next civil year. Automate the image access and processing, very time consuming, would increase the number of RS products used in forest monitoring and save time. Also, automatic approaches to detect and map forest cover change in PRODES would provide annual maps and deforestation rates earlier and increase the number of monitoring products, improving significantly the PRODES agenda.

However, the real challenge is to succeed in automatization without reducing the data quality and keeping the data compatible with the historical series. These are crucial points as the National Government has commitments to reduce and control deforestation, which need explicit and measurable targets along time, and so, deforestation values comparable to past data.

\section{CONCLUSIONS}

These review, aimed to provide the reader a rather comprehensive overview of the valuable advances that have taken place, or shall be incorporated into the deforestation monitoring systems in Brazil. Monitoring Brazilian Amazon forest is a tough task because of its huge extension, socioenvironmental heterogeneity and spatio-temporal dynamic. Despite this, the INPE experts provided the most accurate, consistent, continuous and recognized historical series of tropical deforestation data and supported deforestation combat and control actions with precise early detection information, through PRODES and DETER projects.

The hyper-availability of RS data, the recent initiative of BDC and promising Machine Learning techniques applied to land cover change detection based on ARD, allowed INPE to reinforce its central role in Tropical Forest Monitoring. By proposing innovations on its Monitoring Program and preserving the know-how acquired during more than 30 years of deforestation monitoring, INPE continues to improve Brazilian land cover products and works to maintain data compatible with the historical series.

\section{ACKNOWLEDGEMENTS}

This work was founded by the National Council of Technological and Scientific Development - CNPq, through project MONITORAMENTO DOS BIOMAS BRASILEIROS POR SATÉLITE - CONSTRUÇÃO DE NOVAS CAPACIDADES process: 444418/2018-0, supported by the National Institute for Space Research (INPE).

\section{REFERENCES}

Abreu, E. S. , Fonseca, L. M. G. , Santos, C. P. F. d., Ribeiro, V. O.: 2013. Cloud detection tool - Uma ferramenta para a detecção de nuvens e sombras em imagens de satélite. In: Proceedings of Brazilian Remote Sensing Simposium, Foz do Iguaçu, Brasil, pp. 4234-4241.

Adarme, M. O.; Feitosa, R. Q.; Happ, P. N.; Almeida, C. A.; Gomes, A. R.: 2020. Evaluation of deep learning techniques for deforestation detection in the Brazilian Amazon and Cerrado biomes from remote sensing imagery. Remote Sensing, 12, 6, 910. http://dx.doi.org/10.3390/rs12060910.

Almeida, C. A., Valeriano, D. M., Maurano, L., Vinhas, L., Fonseca, L. M. G., Silva, D., Santos, C. P. F., Martins, F. S. R. V., Lara, F. C. B., Maia, J. S., Profeta, E. R., Santos, L. O., Santos, F. C. O., Ribeiro, V.: 2020. Deforestation monitoring in different Brazilian biomes: Challenges and lessons, ISPRS Ann. 
Photogramm. Remote Sens. Spatial Inf. Sci., IV-3/W2-2020, 47-52, https://doi.org/10.5194/isprs-annals-IV-3-W2-2020-472020.

Almeida, C. A., Maurano, L. E. P., Valeriano, D. D. M., Camara, G., Vinhas, L., Gomes, A. R., Monteiro, A. M. V., Souza, A. A. A., Renno, C. D., Silva, D. E., Adami, M., Escada, M. I. S., Mota, M., Kampel, S. A. Methodology for Forest Monitoring used in PRODES and DETER projects. São José dos Campos: INPE, version: 2021-01-26. IBI: <8JMKD3MGP3W34R/443H3RE>. Available in http://urlib.net/rep/8JMKD3MGP3W34R/443H3RE Accessed in $25 / 04 / 2021$.

Assis, L. F. F. G., Ferreira, K. R., Vinhas, L., Maurano, L., Almeida, C., Carvalho, A., Rodrigues, J., Maciel, A., Camargo, C. : TerraBrasilis: 2019. A Spatial Data Analytics Infrastructure for Large-Scale Thematic Mapping. ISPRS Int. Journal of GeoInformation. 8(11), 513 https://doi.org/10.3390/ijgi8110513

Belgiu, M., Drăguţ, L.: 2016. Random Forest in Remote Sensing: A Review of Applications and Future Directions. ISPRS Journal of Photogrammetry and Remote Sensing, 114, Abril, 24-31. doi:10.1016/j.isprsjprs.2016.01.011.

Camara, G., Vinhas, L., Ferreira, K.R, Queiroz, G.R., Cartaxo, R.M.S., Monteiro, A.M.V., Carvalho, M.T., Casanova, M.A., Freitas, U.M.: 2008. TerraLib: An Open Source GIS Library for Large-Scale Environmental and Socio-Economic Applications. Chapter 12. In:G.B. Hall, M.G. Leahy (eds.), Open Source Approaches in Spatial Data Handling. Advances in Geographic Information Science 2, Springer-Verlag Berlin Heidelberg 2008.

Camara, G., Simões, R., Andrade, P. Maus, V., Sanchez, A., Assis, L., Santos, L., Ywata, A., Maciel, A., Vinhas, L., Ferreira, K., Queiroz, G.: 2018. Sits e-sensing/sits: Version 1.12.5. dec. 2018. Available from: https://doi.org/10.5281/zenodo.1974065

Claverie, M., Ju, J. Jeffrey G. Masek, J.G, Dungan, J.G, Vermote, E.F., Roger, J.C., Skakun, S.V., Justice, C.: 2018. "The Harmonized Landsat and Sentinel-2 Surface Reflectance Data Set. Remote Sensing of Environment , 219,December, 14561. doi:10.1016/j.rse.2018.09.002.

Defries, R. S., Townshend, J.R.G.: 1999. Global Land Cover Characterization from Satellite Data: From Research to Operational Implementation?. Gcte/Lucc Research Review. Global Ecology and Biogeography 8, 5, 367-79. doi:10.1046/j.1365-2699.1999.00139.x.

Dias, L., Fernando, C.P. Pimenta, A., Santos, B., Costa, M.H, Ladle. R.J.: 2016. Patterns of Land Use, Extensification, and Intensification of Brazilian Agriculture. Global Change Biology, May, n/a-n/a. doi:10.1111/gcb.13314.

Diniz, C., De Almeida Souza, A., Santos, D., Correa Dias, M., Cavalcante da Luz, N., Vidal de Moraes, D., Ana Maia, J., Gomes, A.R., Narvaes, I.S., Valeriano, D., et al. DETER-B: The new amazon near real-time deforestation detection system. IEEE J. Sel. Top. Appl. Earth Obs. Remote Sens. 2015, 8, 3619 3628 .

Doblas, J.,, Shimabukuro, Y., Sant'Anna, S., Carneiro, A., Aragão, L., Almeida, C. : 2020. Optimizing Near Real-Time Detection of Deforestation on Tropical Rainforests Using
Sentinel-1 Data. Remote Sensing. 12, 3922. https://doi.org/10.3390/rs12233922.

Ferreira K. R. et al. :2020a. Using Remote Sensing Images and Cloud Services on Aws to Improve Land Use and Cover Monitoring, 2020a. IEEE Latin American GRSS \& ISPRS Remote Sensing Conference (LAGIRS), Santiago, Chile, 2020, pp. 558-562, doi: 10.1109/LAGIRS48042.2020.9165649.

Ferreira, K.R., Queiroz, G.R., Vinhas, L., Marujo, R.F.B., Simoes, R.E.O., Picoli, M.C.A., Camara, G., Cartaxo, R., Gomes, V.C.F., Santos, L.A., Sanchez, A.H., Arcanjo, J.S., Fronza, J.G., Noronha, C.A., Costa, R.W., Zaglia, M.C., Zioti, F., Korting, T.S., Soares, A.R., Chaves, M.E.D., Fonseca, L.M.G.: 2020b. Earth Observation Data Cubes for Brazil: Requirements, Methodology and Products. Remote Sens., 12, 4033.

Freitas, U. M., Ribeiro, V. O., Queiroz, G. R., Petinatti, M. R., Abreu, E. S.: 2007. The Amazon Deforestation Monitoring System. OSGeo Journal. v. 3. ISSN 1994-1897.

Funcate, Inpe: 2021. Biomas - Monitoramento Ambiental dos Biomas Brasileiros por Satélites. Available in http://biomas.funcate.org.br/. Accessed in 25/04/2021.

Funcate, Inpe: 2021. Biomas - Monitoramento Ambiental dos Biomas Brasileiros por Satélites. Available in http://biomas.funcate.org.br/. Accessed in 25/04/2021.

Godar, J., Gardner, T.E Jorge Tizado, J., Pacheco, P. : 2014. Actor-Specific Contributions to the Deforestation Slowdown in the Brazilian Amazon. Proceedings of the

National Academy of Sciences of the United States of America 111 (43): 15591-96. doi:10.1073/pnas.1322825111.

Goodfellow, I., Bengio, Y., Courville, A.: 2016. Deep Learning. MIT press.

Hansen, M.C., Potapov, P.V., Moore, R., Hancher, M., Turubanova, S., Tyukavina, A., Thau, D., Stehman, S., Goetz, S., Loveland, T.: 2013. High-resolution global maps of 21stcentury forest cover change. Science 2013, 342, 850-853.

Hansen, M.C., Loveland, T.R: 2012. A Review of Large Area Monitoring of Land Cover Change Using Landsat Data. Remote Sensing of Environment 122 (July). Elsevier Inc.: 66-74. doi:10.1016/j.rse.2011.08.024.

Kalamandeen, M., Gloor, E., Mitchard, E. et al.: 2018. Pervasive Rise of Small-scale Deforestation in Amazonia. Sci Rep 8, 1600 (2018). https://doi.org/10.1038/s41598-018-193582.

Kintisch, E.: 2007. Carbon Emissions: Improved Monitoring of Rainforests Helps Pierce Haze of Deforestation. Science, 316, 5824, 536-537.

National Institute for Space Research (INPE): 2021a. FIP EM Cerrado - Monitoramento do Desmatamento no Cerrado Brasileiro por Satélite, FIP FM Cerrado. Available in http://cerrado.obt.inpe.br/. Acesso em: 25/04/2021.

National Institute for Space Research (INPE): $2021 \mathrm{~b}$. Terrabrasilis 2021. Available at: http://terrabrasilis.dpi.inpe.br/. Accessed in: 25/04/2021. 
Maurano, L.E.P., Escada, M.I.S., Renno, C.D., 2019. Padrões espaciais de desmatamento e a estimativa da exatidão dos mapas do PRODES para Amazônia Legal Brasileira. Ciênc. Florest. [online]. 29(4), pp.1763-1775. Epub Feb 10, 2020. ISSN 1980-5098 https://doi.org/10.5902/1980509834380.

Messias, C. G., Silva, D. E. , Belluzo, A. P ., Barradas, D. C. M.: 2020. Tendências atuais e identificação de novas frentes de desmatamento na Amazônia Legal Brasileira. In: IX Simpósio de Estudos e Pesquisas em Ciências Ambientais na Amazônia, Belém. Ann. IX Simpósio de Estudos e Pesquisas em Ciências Ambientais na Amazônia.

Messias, C.G., Silva, D., Brasil, M., Souza, T., Almeida, C. 2001a (No prelo). Analysis of deforestation rates and their drivers in the Brazilian Legal Amazon during the last three decades. Raega - O Espaço Geográfico em Análise. Available online: https://revistas.ufpr.br/raega.

Messias, C.G., Silva, D.E., Mauranol, L., Almeida, C.,: 2021b Dinâmica espaço-temporal das duas últimas décadas de desmatamento na Amazônia Legal Brasileira. In: VII Congresso Brasileiro de Educação Ambiental Aplicada e Gestão Territorial.

Mountrakis, G., Im, J., Ogole, C.: 2011. Support Vector Machines in Remote Sensing: A Review. ISPRS Journal of Photogrammetry and Remote Sensing, 66, 3, 247-59. doi:10.1016/j.isprsjprs.2010.11.001.

Ometto, J. P., Aguiar, A. P. D., Martinelli, L. A.: 2011. Amazon deforestation in Brazil: effects, drivers and challenges. Carbon Management, 2 (5), p. 575-585.

Picoli, M. C. A., Simoes, R., Chaves, M., Santos, L. A., Sanchez, A., Soares, A., Sanches, I. D., Ferreira, K. R. and Queiroz, G. R.. CBERS Data Cube: A Powerful Technology for Mapping and Monitoring Brazilian Biomes. In: XXIVth International Society for Photogrammery and Remote Sensing (ISPRS) Congress. Virtual Event. August 31 to September 2, 2020.

Portillo-Quintero, C, Hernández-Stefanoni, J. L., ReyesPalomeque, G., Subedi, M. : 2021. The Road to Operationalization of Effective Tropical Forest Monitoring Systems. Remote Sensing, v. 13, n. 7, p. 1370, 2 abr. 2021.

Rajão, R., Georgiadou, Y., 2014: Blame Games in the Amazon: Environmental Crises and the Emergence of a Transparency Regime in Brazil. Global Environmental Politics, 14 (4), November 2014, 97-115. doi:10.1162/GLEP_a_00259.

Rosa, I.M.D., Souza, C. \& Ewers, R.M.: 2012. Changes in size of deforested patches in the Brazilian Amazon. Conserv. Biol., 26, 932- 937.

Sanchez, A., Picoli, M., Andrade, P.R., Simões, R. Santos, L.,Chaves, M., Begotti, R.,Camara, G.: 2019. Land Cover Classifications of Clear-cut Deforestation Using Deep Learning. In: Simpósio Brasileiro de Geoinformática (GEOINFO), 2019, São José dos Campos. Annal of $20^{\circ}$ Simpósio Brasileiro de Geoinformática. São José dos Campos: INPE, 2019. ISSN 2179-4847. IBI: <8JMKD3MGPDW34R/3UFDE4P>.

Tardin, A. T., Santos, A. P., Lee, s. C.L., Maia, F.C.S., Mendonça, F.J., Assunção, G.V., Rodrigues, J.E., Abdon, M.M., Novaes, R. A., Chen, S,C., Duarte, V., Shimabukuro,
Y.E.: 1979. Levantamento de áreas de desmatamento na Amazônia Legal através de imagens do Satelite Landsat. São José dos Campos, 62 p., Technical Report, INPE-1411NTE/142.

Valeriano, D. M., Narvaes, I. S., Maia, J. S., Gomes, A. R., Diniz, C. G., Souza, A. A. A. Metodologia do sistema DETER B (sistema de detecção do desmatamento e alterações na cobertura florestal em tempo quase real). Mapeamento de alertas com imagens dos sensores AWiFS-Resourcesat-2 e WFI-Cbers-4. São José dos Campos: INPE, 2016. 18 p. IBI: <8JMKD3MGP3W34P/3LQKMBL>.(sid.inpe.br/mtc-m21b/ 2016/06.03.17.54-RPQ). Available in: <http://urlib.net/rep/ 8JMKD3MGP3W34P/3LQKMBL>.

Vinhas, L., Queiroz, G.R., Ferreira, K.R., Camara, G. : 2017. Web Services for Big Earth Observation Data. Revista Brasileira de Cartografia 69 (5).

West, T.A.P., Fearnside, P.M., 2021: Brazil's conservation reform and the reduction of deforestation in Amazonia, Land Use Policy, 100, ISSN 0264-8377. doi.org/10.1016/j. landusepol.2020.105072. 